HoST - Journal of History of Science and Technology

Vol. 14 , no. 1 , June 2020, pp. 52-78

\title{
Standard Making in Cytogenetics: the Manufacture, Circulation and Reproduction of Chromosome Images
}

\author{
María Jesús Santesmases \\ Instituto de Filosofía, Consejo Superior de Investigaciones Científicas (CSIC), Madrid \\ mariaj.santesmases@cchs.csic.es
}

\begin{abstract}
The first reliable pattern of the human chromosome set was manufactured between the late 1950s and early 1960s. This paper will account for the historical background of such reliability, of the production of a reference, an image, the schematic figure - the ideogram - that represented what would from then on be held in the minds of medical practitioners and laboratory scientists of human cytogenetics as the cytological identity of being human. Human genetics as a history of images and the skills of drawing, making photo(micro) graphs and diagrams, developed through a reference drawn on the basis of the consensus reached by a small group of early human cytogeneticists in Denver in 1960. Schemes and idealizations, as well as the fully realistic transposition of the contours and interiors of each chromosome, participated in the emergence of a particular, specific and enduring way of representing the tiny parts of the cell where division began, and accounting for both the forms and function of chromosomes at the origins of medical genetics.
\end{abstract}

Keywords: genetics; visual cultures; cytogenetics; human chromosomes 
In 1960, Annals of Human Genetics, the official journal of London's Institute of Human Genetics, published an article entitled "A proposed standards system of human mitotic chromosomes (Denver, Colorado)." The report was preceded, as if an introduction or foreword, by an "Editorial Comment," synthesizing what was to come. The comment included an image of twenty-four chromosomes, those numbered one to twenty-two of different sizes, and two named $\mathrm{X}$ and $\mathrm{Y}$, together with two paragraphs describing the drawing and a table showing the average length of each chromosome. Drawn in black and ordered by size, the lines defining chromosome shapes were straight and elegant. This first page was signed with initials: L. P., those of Lionel Penrose. ${ }^{1}$ At the time, Penrose was Galton Professor of Eugenics at University College London (UCL), head of the Galton Laboratories and the editor of the journal publishing the report. $^{2}$ The page signed with his initials and those that followed - a total of seven including the full names and positions of participants at the Denver conference - indicate Penrose's deep interest in the conference's subject matter, which he summarized here in a diagram of slender, idealised chromosome shapes.

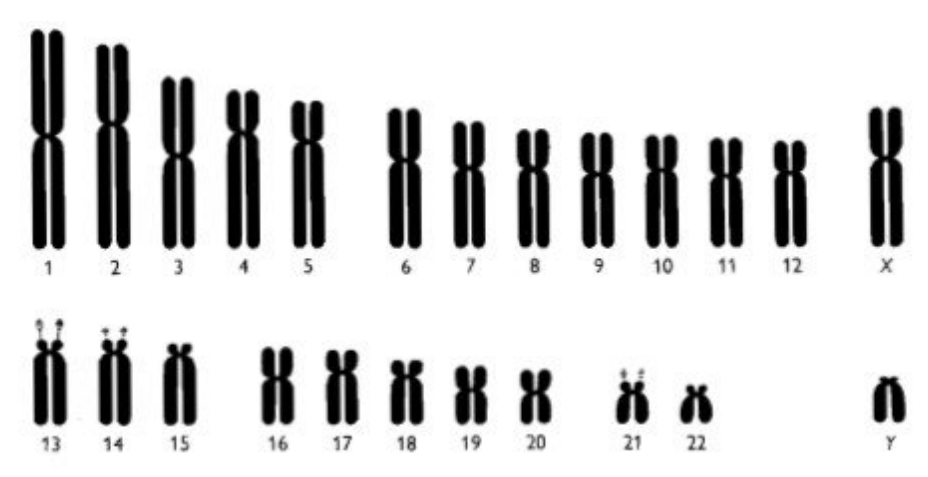

Figure 1 - Drawing of human chromosomes, L. P., "A proposed standards system of human mitotic chromosomes (Denver, Colorado). Editorial Comment," Annals of Human Genetics 24, no. 4 (1960):

319. Reproduced with permission from John Wiley and Sons. Copyright 1960

By 1960, practitioners of cytology were already familiar with the forms of chromosomes. A genealogy can be traced back to historicize the social life of chromosome shapes, the techniques and mindful hands that provided the new codes of living beings these tiny figures of the cell became from the 1880s onwards. Such genetic morphologies belonged to a visual epistemology that shared practices with botany and zoology, in a superimposed set of experiments from the

\footnotetext{
${ }^{1}$ L. P., "A proposed standards system of human mitotic chromosomes (Denver, Colorado). Editorial Comment," Annals of Human Genetics 24, no. 4 (1960): 319.

2 On Lionel Penrose, see Daniel J. Kevles, In the Name of Eugenics: Genetics and the Uses of Human Heredity (Cambridge, MA: Harvard University Press, 1995); Jean-Paul Gaudillière, "Bettering Babies: Down's Syndrome, Heredity and Public Health in Post-war France and Britain," in Images of Disease: Science, Public Policy and Health in Post-war Europe, eds. Ilana Lowy and John Krige, 89-108 (Brussels: European Commission, 2001).
} 
two disciplines for cytologists to observe and provide evidence of the existence and ontology of cells in living beings.

Images became evidence to be witnessed through the microscope, while the methods for producing them not only involved making the preparative slide to observe cell parts, but also drawing the spectacle. The experience of making the cell and its inner workings visible was at the very origins of cytological practices, and chromosomes thus participated in the circulation of the cellular knowledge such shapes embodied. ${ }^{3}$ Through circulation, images were made reliable: not only because the methods for obtaining them were reproducible but because with such reproduction in different settings, the end product - the chromosome on a paper became true, a reliable part of the cell. As a feedback loop created forms while providing codes for the life sciences - mutually reinforcing practices - chromosome shapes became familiar to scientists and medical practitioners, at least to the expanding expert community whose members designed experiments to secure these images. An entire epistemology of creating such knowledge circulated, including practices at the laboratory bench where slides were manufactured. These slides were composed of tiny points able to be magnified, each showing sets of forms belonging to a single cell. ${ }^{4}$

Forms have often been at the core of knowledge about living beings, from embryos to cells. Here I present a historical and epistemic relationship between natural history's drawings and images, and those from embryology and early cytology, which were at the roots of cytogenetic visual cultures. Chromosomes joined a long history of the natural sciences, from natural history to contemporary biomedicine, articulated around representations of natural forms reconstructed in parts - plant and animal parts, plus entire bodies in various positions, and viewed from different angles - that acquired the temporalities and localities of visual styles in the arts of both naturalists and artist illustrators. ${ }^{5}$ The construction of consensus on the meaning of images originated in the cytology practices that had contributed to a pioneering

\footnotetext{
${ }^{3}$ María Jesús Santesmases and Edna Suárez-Díaz, "A cell-based epistemology: Human genetics in the era of biomedicine," Historical Studies in the Natural Sciences 45, no. 1 (2015): 1-13.

${ }^{4}$ On the method, see María Jesús Santesmases, "The human autonomous karyotype and the origins of prenatal testing: Children, pregnant women and early Down's syndrome cytogenetics, Madrid 19621975," Studies in History and Philosophy of Biological and Biomedical Sciences 47 (2014): 142-53.

5 There is a rich body of historical work on visual cultures in the sciences, following on from the groundbreaking work on the centrality of visual cultures in early geology and the "conceptual" use of images by Martin Rudwick, "The emergence of a visual language for geological science 1760-1840," History of Science 14, no. 3 (1976): 149-195; Horst Bredekamp, "A neglected tradition? Art history as Bildwissenschaft," Critical Inquiry, 29, no. 3 (2003): 418-28. For more recent contributions, see Sachiko Kusukawa, Picturing the Book of Nature: Image, Text, and Argument in Sixteenth-century Human Anatomy and Medical Botany (Chicago: University of Chicago Press, 2012); Daniela Bleichmar, Visible Empire: Botanical Expeditions and Visual Culture in the Hispanic Enlightenment (Chicago: University of Chicago Press, 2012). A very useful review is José Ramón Marcaida, "Pictures and Conversation: How to Study the Visual Cultures of Science,” Isis, 107, no. 1 (2016): 134-39.
} 
understanding of heredity (Vererbung) by August Weismann at the end of the nineteenth century, and continued through to early human cytogenetics in the 1960s (see below). ${ }^{6}$

The art of producing good slides, that is, slides able to be amplified and drawn with the help of the camera lucida, was not the only agent involved; the eye was also being trained to recognise such forms and their biological meaning. Inner cell-parts were observed through the microscope then magnified to be drawn and studied in detail: that is, to be reconstructed as drawing codes by cytologists and naturalists.

It was between the late 1950s and early 1960s that a reliable pattern of the human chromosome set was first manufactured. This paper will account for the historical background of such reliability, of the production of a reference, an image, the figure that represented on a scheme - the ideogram - what would from then on be held in the mind of medical practitioners and laboratory scientists of human cytogenetics, as the cytological identity of being human.

The history of the Denver conference, from whose consensus Penrose proceeded to sign his statement regarding "a proposal for a standard system of nomenclature" and include a referent image of the human chromosome set - the karyotype - has been narrated in the history of twentieth-century life sciences for various purposes. ${ }^{7}$ It was at this conference held at the University of Denver, Colorado, where styles of representing chromosomes were negotiated, numbers were assigned to each of the twenty-three chromosome pairs, and chromosome lengths were agreed upon as being reliably reproduced, by all the seventeen signing scientists - fourteen participants and three who signed as counsellors. Convened by expert cytologist Theodore Puck from the University of Denver Medical School, the group of scientists included one women, Patricia Jacobs, from Edinburgh, and a small group of pioneers in the field of human

${ }^{6}$ Gloria Robinson, A Prelude to Genetics: Theories of a Material Substance of Heredity - Darwin to Weismann (Lawrence, Kansas: Coronado Press,1979), chapter 7; see also Frederick B. Churchill, August Weismann: Development, Heredity, and Evolution (Cambridge, MA: Harvard University Press, 2015) and longer historization in Staffan Müller-Wille and Hans-Jörg Rheinberger, A Cultural History of Heredity (Chicago: University of Chicago Press, 2012).

7 Tao-Chiuh Hsu, Human and Mammalian Cytogenetics: an Historical Perspective (New York: Springer, 2012); Kevles, In the Name of Eugenics; M. Susan Lindee, Moments of Truth in Genetic Medicine (Baltimore: Johns Hopkins University Press, 2005); Andrew J. Hogan, Life Histories of Genetic Disease: Patterns and Prevention in Postwar Medical Genetics (Baltimore: Johns Hopkins University Press, 2016). On the origins of human cytogenetics see Soraya de Chadarevian, "Mice and the reactor: the 'genetics experiment' in 1950s Britain," Journal of the History of Biology 39, no. 4 (2006): 707-735; Soraya de Chadarevian, "Mutations in the nuclear age," in Making mutations: objects, practices, contexts, eds. Luis Campos and Alexander von Schwerin, 179-88 (Berlin: Max-Planck Institut für Wissenschafts Geschichte, 2010); María Jesús Santesmases, "Size and the centromere: translocations and visual cultures in early human genetics," in Campos and von Schwerin, Making Mutations, 189-208; María Jesús Santesmases, "Circulating biomedical images: Bodies and chromosomes in the post-eugenic era," History of Science 55, no. 4 (2017): 395-430; María Jesús Santesmases, "Human Chromosomes and Cancer: Tumors and the Geographies of Cytogenetic Practices, 1951-1956," Historical Studies in the Natural Sciences 45, no. 1 (2015): 85-114. 
cytogenetics, among them Albert Levan from the University of Lund (Sweden); Joe Hin Tjio, from the NIH in Bethesda, Maryland (US); Sajiro Makino from Hokkaido University in Sapporo (Japan); and David A. Hungerford from the Institute of Cancer Research in Fox Chase, Pennsylvania (US). ${ }^{8}$

This paper aspires to contribute to the historiography of human chromosomes by reconstructing the visual cultures through which the proposed standard, the reliable pattern published by Lionel Penrose immediately after the conference in 1960, was produced.

In experimentation, reliability refers to the capacity for reproduction in a repeated experiment: that is, an epistemic practice with similar, at times identical results as those obtained by the first experience, described in a publication or other means of circulating information. However, experiments do not travel easily and take time to be regarded as reliable. In the case of cytological images, reliability meant comparable images would be obtained from similar human material, from different people who all shared, or were expected to share, the same number of chromosomes. Although this number was ontologically significant, shape still played a central role. ${ }^{9}$

Throughout the succession of events, a visual epistemology and practices were circulated and reproduced. A wide geography produced and reproduced practices, interchanged biological meanings while sharing methods and substances to make chromosomes visible. The cell division was an event to be witnessed, an event that placed chromosomes, and the methods for obtaining clear images of them, centre-stage. ${ }^{10}$

As well as transitions, journeys, laboratories and collections, this story is about a history of shapes, their final consolidation drawn by Mr. A. J. Lee at Penrose's laboratory and the stabilization of this set of forms as a reference for the human karyotype. ${ }^{11}$ Drawings have travelled all around the globe, as the early modern history of science and medicine has shown.

\footnotetext{
${ }^{8}$ In addition to Lindee, Moments of Truth, see the report by Hamerton (Nobel conference) in Torbjörn Oskar Caspersson and Lore Zech, eds., Chromosome Identification: Technique and Applications in Biology and Medicine: Proceedings of the Twenty-third Nobel Symposium Held September 25-27, 1972 at the Royal Swedish Academy of Sciences, Stockholm (Stockholm: Nobel Foundation, 1973).

9 On numbers, see Aryn Martin, "Can't any body count? Counting as an epistemic theme in the history of human chromosomes," Social Studies of Science 34, no. 6 (2004): 923-48; Malcolm Jay Kottler, "From 48 to 46: Cytological technique, preconception, and the counting of human chromosomes," Bulletin of the History of Medicine 48, no. 4 (1974): 465-502.

${ }_{10}$ On seeing cells and chromosomes at that time, see Jane Maienschein, "From presentation to representation in EB Wilson's The Cell,” Biology and Philosophy 6, no. 2 (1991): 227-254; Helga Satzinger, "Theodor and Marcella Boveri: chromosomes and cytoplasm in heredity and development," Nature Reviews Genetics 9, no. 3 (2008): 231-38.

${ }^{11}$ I atribute these chromosome drawings to A. J. Lee based on Penrose's ackowledgements of Lee in the 1959 and 1963 editions of Penrose's, The Biology of Mental Defects (London: Sidgwick and Jackson, 1954). See Santesmases, "Circulating."
} 
Plant drawings were some of the earliest, composed of certain parts arranged in a particular code; the historical reconstruction of botanical illustrations has inspired this essay on the visual cultures of chromosome imaging. ${ }^{12}$

The term reproduction is used here in association with circulation. By reproduction I mean a set of successive experiments of adoption and adaptation, the modification and representation of a given laboratory experience. Once produced for the first time in a laboratory, the experiment travelled and became established in the geography of cytogenetics. ${ }^{13}$ Reproduction involved moves through both space and time, trajectories of travels, journeys of knowledge and practices. By following the movement of practices from one place to another, from one time to another, this paper aims to demonstrate the centrality of the travels of a scientific practice - that of cytogenetics - and the reproductive processes involved: the conducting of experiments by those who understood the terms and methods written by a colleague - some not described in full but taken for granted by expert cytologists - and the results participating in the geographical times of contemporary human genetics.

This paper will situate laboratory experiences as cultures involved in the emergent ontologies that chromosome shapes became, entities able to provide and produce explanations. Intersections took place between experimental methods and images, between visual cultures and laboratory experiences in the preparation of microscopic slides, precisely because these experiments were performed with the intention of producing good, clear images. Taking the epistemology of biology as a visual culture involved an exploration of cytogenetic images - that is, chromosomes - and the repetitions in laboratory practices to stabilise both knowledge and practices, methods for obtaining images, the images themselves and the ability to reproduce experiments with similar results: that is, similar images from similar samples. I will bring all these circumstances together in a single narrative in an attempt to explain how the pattern, the style of representing - drawing, creating shapes - human chromosomes was made reliable on the basis of chromosome imaging that originated before 1960, and through the circulation and reproduction of the methods that made such chromosomes visible. Practices of botany and zoology, the reliable methods to make chromosomes visible in those domains, and the chromosome shapes thus manufactured, were the basis upon which human cytogenetics was produced and circulated. This is also a proposal for the historical reconstruction of standard

\footnotetext{
${ }^{12}$ In addition to Rudwick, "The emergence of a visual language," Kusukawa, Picturing the Book of Nature and Bleichmar, Visible Empire; see the review by Irina Podgorny, review of Visible Empire: Botanical Expeditions and Visual Culture in the Hispanic Enlightenment by Daniela Bleichmar, Revista Hispánica Moderna 68, no. 1 (2015): 101-104, and references therein.

${ }^{13}$ Unlike David Edgerton, in his The Shock of the Old: Technology and Global History since 1900 (London: Profile books, 2011), my interest here is to focus on the circulation, travels and concept of reproduction rather than uses, by emphasizing such travels and the different ways of performing experiments while providing results that shared styles of producing coded images.
} 
making in the life sciences. The circulation I focus on involves both time and geography, the creation of maps of imaging production in which images were the main epistemic object, securing a central ontology for construction of the biomedical domain that human cytogenetics became ${ }^{14}$.

\section{Series: the Ordered Images of Cells and Chromosomes}

The ordering of scientific objects has inspired reflections and contributed to those presented here. Among the examples I studied are those published by Haeckel (1874), insightfully analysed by Nick Hopwood. ${ }^{15}$ Series of images constructed order, produced new images through reconstruction of the set following a given reasoning, and created confidence. Haeckels's order could be placed in front of the images drawn by Penrose's assistant, Mr A. J. Lee (see figure 1). Both recreated a set giving order to what could otherwise have been a random array of images found in the microscopic slide. Each recreation of such order manufactured a self-referencing set. ${ }^{16}$

This culture of representation, the practice of both making order in the karyotype and accounting for its function, has its roots in botany, zoology and cytology, all domains of knowledge and experience that have presented patterns of images, codes for their representation - including plant forms from overseas for the empire(s) - plus the use of paper technologies, and the travels of all these through time and geography. Nature travelled when drawn onto paper and sent wherever the images were expected. ${ }^{17}$ These images represented nature as well as the authority of the expedition's leader, usually a man who did not draw himself but directed and supervised a drawing team. The names of team members have not often been preserved - unknown artists - and are difficult to discover. ${ }^{18}$ While in art the artist is the agent, in the sciences an academic or scientific authority is the protagonist, and those who drew were regarded as technical assistants. In many cases, scientific leaders had drawn earlier in their careers, creating new orders from a view of nature presented in both words and images, while

\footnotetext{
${ }^{14}$ On epistemic objects see Hans-Jorg Rheinberger, Toward a history of epistemic things: Synthesizing proteins in the test tube (Stanford: Stanford University Press, 1997) and Hans-Jörg Rheinberger, On historicizing epistemology: an essay (Stanford: Stanford University Press, 2010).

15 Nick Hopwood, Haeckel's Embryos: Images, Evolution, and Fraud (Chicago: University of Chicago Press, 2015); Nick Hopwood, Simon Schaffer, and Jim Secord, "Seriality and scientific objects in the nineteenth century," History of Science 48, no. 3-4 (2010): 251-85.

${ }^{16}$ Inspired by Ernst H. Gombrich, The Sense of Order: A Study in the Psychology of Decorative Art (Oxford: Phaidon, 1979).

${ }^{17}$ See the review of Bleichmar's book by Podgorny, review of Visible Empire, and references therein; and also, Marcaida, "Pictures and Conversation"; Bredekamp, "A neglected tradition?"

18 Montserrat Cabré i Pairet, "Autoras sin nombre, autoridad femenina (siglo XIII)," en Las sabias mujeres II (siglos III-XVI): homenaje a Lola Luna, ed. María del Mar Graña Cid, 59-74 (Madrid: Asociación Cultural Al-Mudayna, 1995).
} 
creating evidence of biological functions through the same mindful hand.

The cytologist, Edmund Beecher Wilson, drew cell forms himself during the 1890s, not only the shapes he observed through the microscope, but diagrammatic forms, intended to establish order in what he regarded at times as the confused set of images obtained from looking at the cell. ${ }^{19} \mathrm{He}$ depicted the contours of the cell as perfectly circular, despite having reproduced such contours as non-lineal, as imperfect forms. Wilson was idealising, diagrammatizing, schematizing cell shapes, participating in this culture of stretching lines to provide simplified visions of life and nature (see figure 2).

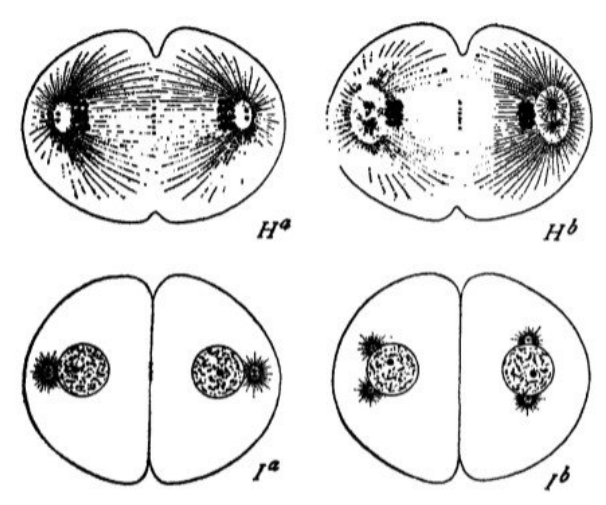

Figure 2 - Mitosis as drawn by Edmund Wilson, qualified by him as a "diagram," that is, schematized: Edmund B. Wilson, The Cell in Development and Heredity, 3rd ed., with correction (New York: Macmillan, 1925), 120.

Contemporary with Wilson's diagrams were Theodor Boveri's lithographs in a text published in 1899, the originals of which have been analysed by Helga Satzinger and published as a beautiful series of coloured images. ${ }^{20}$ Held at the University of Würtzburg (Germany), Boveri's lithographs show in detail the interplay between chromosomes and cytoplasm in fertilization. Heredity and embryological development are clarified by what Satzinger has described as "superb visualization techniques." At the time that Theodor and Marcella Boveri were focusing on these tiny entities of the cell nucleus that became visible during cell division when tainted by particular dyes, many scientists had discounted cytology as a useful practice for investigating heredity. Boveri's lines are diagrammatized as lineal, fully and perfectly circular, thus suggesting some idealization of what the Boveri's saw through the microscope. The beautiful lithographed shapes show stretched contours, cells beside one another, fitting together in a lineal way.

A genealogy of cytogenetics situates the Boveri's at its very origins, along with Wilson and

${ }^{19}$ Edmund Beecher Wilson, The Cell in Development and Heredity (London: the Macmillan Company, 1896); Maienschein, "From presentation to representation."

${ }^{20}$ Satzinger, "Theodor and Marcella Boveri." 
Nettie Stevens. Stevens spent some months of the academic year 1901-1902, conducting research with Theodor Boveri at the Naples Experimental Station and Würtzburg University, and in 1908 was able to reveal Drosophila chromosomes. She had developed a technique to make the fruit fly's chromosomes visible in size and number and thus laid the basis for later studies on Drosophila genetics by Thomas H. Morgan's group. Stevens' chromosome drawings show the imperfect, wrinkled or twisted lines of the chromosomes as she observed them through the camera lucida after preparing and tainting the samples. ${ }^{21}$

Based on this pioneering work, in 1915, Drosophila geneticists Thomas H. Morgan, Alfred Sturtevant, Hermann Muller and Calvin Bridges, in their co-authored book The Mechanism of Mendelian Heredity, schematized the fruit fly's chromosome shapes in Morgan's laboratory to present them as stretched lines, and so participated in the stylized representation of cellular entities as diagrams. Evidence provided as both seriality, through repetitions confirming earlier results, and as diagrams, contributed to the manufacturing of chromosomal representation, in sets, repetitions and clear straight lines (see figure 3$).{ }^{22}$

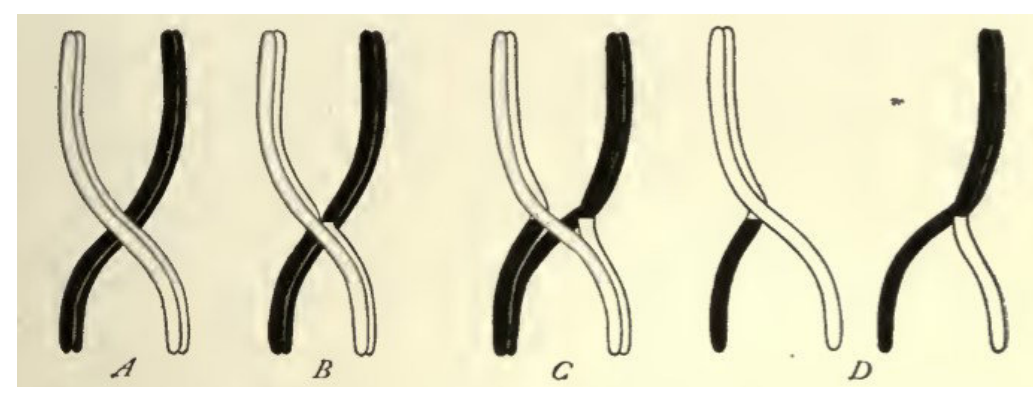

Figure 3 - Diagram of the four stages of crossing over - the interchange of chromosome fragments during cell division. From Thomas Hunt Morgan, Alfred H. Sturtevant, Hermann J. Muller, and Calvin B. Bridges, The Mechanism of Mendelian Heredity (New York: Holt, 1915), 133. Reproduced in Calvin B. Bridges, "Non-disjunction as proof of the chromosome theory of heredity (concluded)," Genetics 1, no. 2 (1916): 107-163, on 121.

Reproduced with permission from the Genetics Society of America.

${ }^{21}$ Nettie M. Stevens, "A study of the germ cells of certain Diptera, with reference to the heterochromosomes and the phenomena of synapsis," Journal of Experimental Zoology 5, no. 3 (1908): 359-74; Marilyn Bailey Ogilvie and Clifford J. Choquette, "Nettie Maria Stevens (1861-1912): her life and contributions to cytogenetics," Proceedings of the American Philosophical Society 125, no. 4 (1981): 292-311; Isabel Delgado Echeverría, El descubrimiento de los cromosomas sexuales: un hito en la historia de la biología (Madrid: CSIC, 2007). See also María Jesús Santesmases, "Women in Early Human Cytogenetics: An Essay on a Gendered History of Chromosome Imaging," Perspectives on Science 28 (2019): 170-200.

${ }^{22}$ On Morgan, see Garland E. Allen, Thomas Hunt Morgan, the Man and his Science (Princeton: Princeton University Press, 1978); on the fly laboratory, see Robert E. Kohler, Lords of the Fly: Drosophila Genetics and the Experimental Life (Chicago: University of Chicago Press, 1994); on Bridges, see the testimony of Morgan himself in Bridges' obituary, Thomas Hunt Morgan, "Calvin Blackman Bridges (1889-1938)," Biographical Memoirs of the National Academy of Sciences USA 22 (1943): 30-50. 
In the acknowledgements, the authors mention Edith Wallace, well-known artist of the Morgan group who draw the flies, for "her skill in making many of the illustrations," and Miss M. L. Hedge, "who has helped us likewise" and may have been the author of the crossing-over diagram, or even Bridges himself, who reproduced the image in later publications of his as single author. ${ }^{23}$

The same culture of presenting evidence is found in the chromosomes depicted by Lillian Vaughan Morgan. ${ }^{24}$ In her paper of 1922, when presenting the case of a Drosophila specimen with three $\mathrm{X}$ chromosomes, two united in a longer one, she included a set of images of these alongside related specimens in the same plate, providing a series of testimonies that either repeated the experiment or, at times, proffered references from the chromosomes of wild-type specimens. Similar drawings were included during this decade in papers published by other Drosophila geneticists. The references created by Stevens and idealized - stretched, simplified by Bridges were reproduced in Vaughan Morgan's drawings, thus contributing to the reliability of what would become an easily identifiable morphology for experts in Drosophila genetics. Vaughan Morgan's reproduction of the method, while contributing to the field with slight modifications, was an instrumental agent. ${ }^{25}$

\section{Lines and Geometry in Chromosome Shapes}

By the end of the 1920s, a young researcher working on maize genetics, Barbara McClintock, presented what she designated a "semi diagrammatic representation" of the chromosome set of Zea mays (see figure 4a). ${ }^{26}$ In her next publication, these rigid, rectangular shapes would be followed by a realistic portrait of a chromosome interchange, a similar phenomenon to that which Bridges had reported in a schematized drawing: the interchanging of chromosome parts. The reconstruction I present here, of shapes and styles of reasoning, of creating and presenting evidence in shapes and sets of shapes, beyond the well-known history of the interchanging of chromosome parts during mitosis (cell division), is centred on images. This visual culture created images as codes, patterns for referencing knowledge about chromosomes yet to come, at the very origins of contemporary genetics, when standards were being constructed, and styles of representing would eventually condense into a diagram representing the human

23 Thomas Hunt Morgan, Alfred H. Sturtevant, Hermann J. Muller, and Calvin B. Bridges, The Mechanism of Mendelian Heredity (New York: Holt, 1915).

${ }^{24}$ For her biography, see Katherine Keenan, "Lilian Vaughan Morgan (1870-1952): Her Life and Work," American Zoologist 23, no. 4 (1983): 867-76.

${ }^{25}$ Lilian Vaughan Morgan, "Non-criss-cross inheritance in Drosophila melanogaster," Biological Bulletin 42 (1922): 267-74.

26 Evelyn Fox Keller, A Feeling for the Organism: the Life and Work of Barbara McClintock (London: Macmillan, 1984); Nathaniel C. Comfort, The Tangled Field: Barbara McClintock's Search for the Patterns of Genetic Control (Cambridge, MA: Harvard University Press, 2009). 
chromosome set.

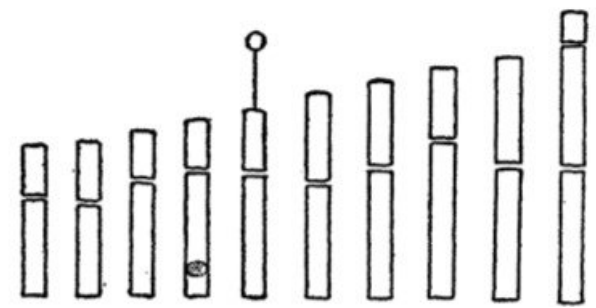

Figure 4a - Semi-diagrammatic representation of the chromosomes of Zea mays, as drawn by Barbara McClintock, "Chromosome morphology in Zea mays," Science 69, no. 1798 (1929): 629. Reproduced with permission from the American Association for the Advancement of Science.

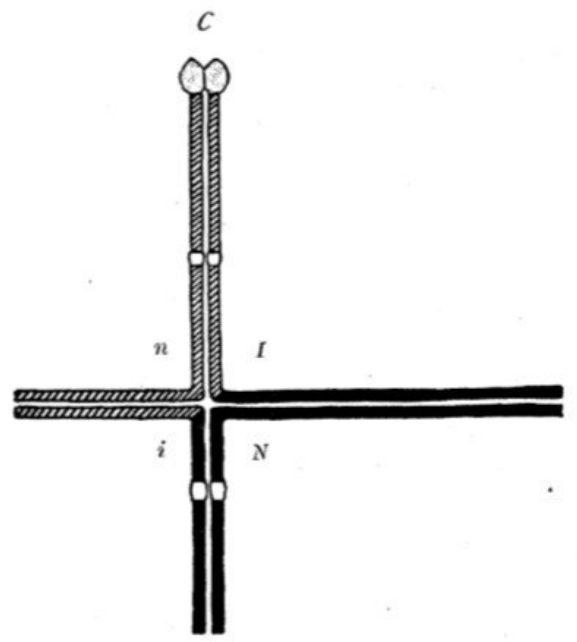

Figure $\mathbf{4 b}$ - Schematic drawing of the crossing-over between two chromosomes of Zea mays. Barbara McClintock, "A cytological demonstration of the location of an interchange between two nonhomologous chromosomes of Zea mays," Proceedings of the National Academy of Sciences of the United States of America 16 no. 12 (1930): 791-796, on 793.

This drawing by Barbara McClintock was followed by a schematized representation of her beautiful, realistic portrait of the interchange of chromosome parts (see figure $4 \mathrm{~b}$ ). Over successive pages, McClintock embraced the technique of helping the reader understand accurate drawings by proffering simpler forms to clarify what is termed "crossing-over" (see figure $4 \mathrm{a}$ and $4 \mathrm{~b}) .{ }^{27}$ Since the 1920 s at least, linearity has been associated with clarity, the logic of which can be found in the powers of geometry as a mathematical representation of space,

\footnotetext{
${ }^{27}$ An inspiration for this reflection was the brief commentary on the subject in their history of gene mapping in maize, by Lee B. Kass and Christophe Bonneuil, "Mapping and seeing: Barbara McClintock and the linking of genetics and cytology in maize genetics, 1928-35," in Classical Genetic Research and its Legacy: The Mapping Cultures of Twentieth-Century Genetics, eds. Hans-Jörg Rheinberger and JeanPaul Gaudillière, 103-130 (London: Routledge, 2004).
} 
even the entire world, with idealistic figures that have captivated the scientific imagination and imaging.

Japanese cytogeneticist, Sajiro Makino, from the Zoological Institute of Hokkaido Imperial University, published a set of serial images of chromosomes of the cricket Oecanthus longicauda in 1932 (see figure 5). As stated in his paper, the research was done "under the guidance" of the renowned Japanese cytogeneticist Kan Oguma, who in the early 1920s had collaborated with Hans von Winiwarter, regarded as "the Belgian authority on human chromosomes." ${ }^{28}$ Makino's series was a set of drawings in which the shapes and numbers of cricket chromosomes were depicted. A variety of cases displaying similar shapes and the same numbers was proof of the genetic characterization of an insect based precisely on chromosome numbers, their shapes and the shape of the whole set. Makino's long career in research on chromosomes, heredity and mutation would eventually see him switch to human cytogenetics with a focus on cancer chromosomes, and, invited as one of the few experts in the field, he participated in the Denver conference in 1960.

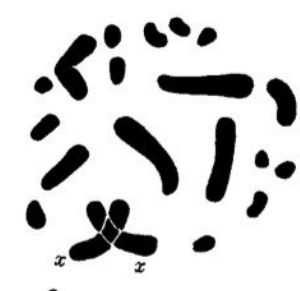

a

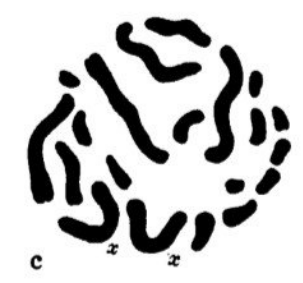

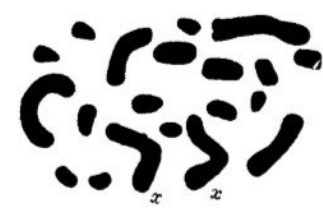

b

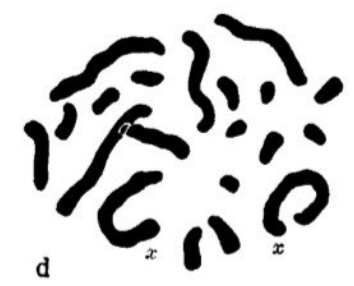

Figure 5 - Metaphase groups of chromosomes from cells of follicle epithelia in the female tree-cricket. Two X chromosomes in each group are noted by the author. Sajiro Makino, "An unequal pair of idiochromosomes in the tree-cricket Oecanthus Longicauda mats,” 北海道帝國大學理學部紀要= Journal of the Faculty of Science Hokkaido Imperial University. Series VI. Zoology 2, no. 1 (1932): 1-37, on p. 14. Reproduced with permission from the Faculty of Science, Hokkaido University.

\footnotetext{
${ }^{28}$ Sajiro Makino, "An unequal pair of idiochromosomes in the tree-cricket Oecanthus Longicauda mats," 北海道帝國大學理學部紀要= Journal of the Faculty of Science Hokkaido Imperial University. Series VI. Zoology 2, no. 1 (1932): 1-35; Hitoshi Kihara, "Foreword," in Human Chromosomes, by Sajiro Makino (Tokyo: Igaku Shoin-Amsterdam-Oxford: North Holland, 1975); Kaori Iida, "Practice and politics in Japanese science: Hitoshi Kihara and the formation of a genetics discipline," Journal of the History of Biology 43, no. 3 (2010): 529-70. On Winiwarter, see Martin, "Can't any body count?" and Kottler, "From 48 to 46."
} 
Geometry and its linearity would certainly become a central culture for idealizing genetics as a visual epistemology, but this domain of biology retained confidence in realistic shapes and contours. After his experiments in the 1920s on animal chromosomes - including differentiating between the white man and "the negro" - that led to forty-eight as the human chromosome number, the skilful cytologist Theophilus Painter apparently abandoned his racist deliberations and focused on Drosophila. ${ }^{29}$ Between 1932 and 1935, Painter presented detailed images depicting the giant chromosomes of Drosophila's salivary gland. He had dissected the salivary gland of Drosophila larvae "about to pupate" to prepare on a slide..$^{30}$

In the images recurrently reproduced in Painter's papers, this large chromosome contained a magnified structure mapping, again, a realistic impression of what he observed when pressing his thumb on the cover of a slide. With this gesture, which broke the cell membrane, the shape of chromosomes appeared as a complex set once the slide preparation had been stained with aceto-carmine (see figure 6). Painter also presented parts of the salivary gland chromosomes as a lineal, stretched - but not diagrammatized - image (see figures 6 and 7). He produced this by uniting camera lucida "sketches of various regions." 31

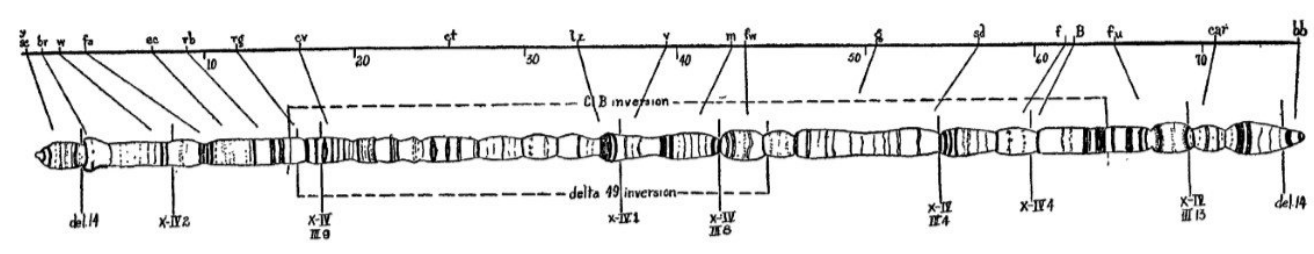

Figure 6 - "A drawing of the X-chromosome made by uniting camera lucida sketches of various regions." Theophilus S. Painter." Theophilus S. Painter, "A new method for the study of chromosome rearrangements and the plotting of chromosome maps," Science 78, no. 2034 (1933): 58586, on 586. Reproduced with permission from the American Association for the Advancement of Science.

29 On his "white" and "negro" chromosomes, see Theophilus Painter, "Studies in mammalian spermatogenesis. II. The spermatogenesis of man,” Journal of Experimental Zoology 37 (1923): 291336, figures on 336.

30 Theophilus S. Painter, "A new method for the study of chromosome aberrations and the plotting of chromosome maps in Drosophila melanogaster," Genetics 19, no. 3 (1934): 175-188.

31 Theophilus S. Painter, "A new method for the study of chromosome rearrangements and the plotting of chromosome maps," Science 78, no. 2034 (1933): 585-86; Theophilus S. Painter, "The morphology of the X chromosome in salivary glands of Drosophila melanogaster and a new type of chromosome map for this element," Genetics 19, no. 5 (1934): 448-69; Theophilus S. Painter, "The morphology of the third chromosome in the salivary gland of Drosophila melanogaster and a new cytological map of this element," Genetics 20, no. 4 (1935): 301-26. 


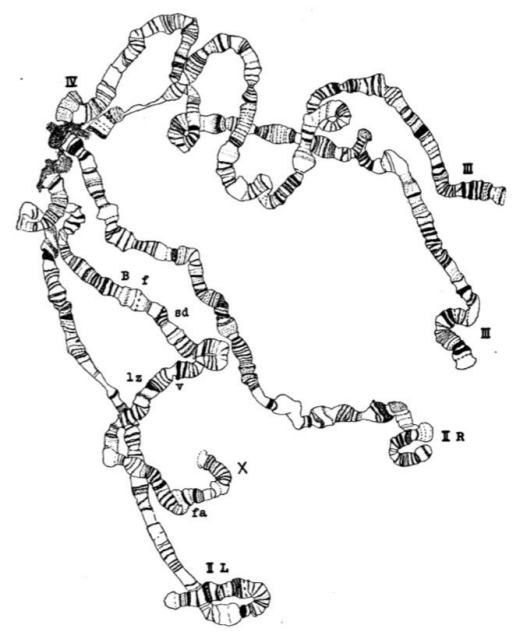

Figure 7 - Chromosomes from Drosophila salivary gland after the nuclear wall was broken by softly pressing on the cover glass. Chromosomes are numbered I-IV. Theophilus S. Painter, "A new method for the study of chromosome aberrations and the plotting of chromosome maps in Drosophila melanogaster," Genetics 19, no. 3 (1934): 175-188, on 179. Reproduced with permission from the Genetics Society of America.

Painter's published images were among the most detailed of the period and remained so for quite some time. Achromatic - untainted - regions differentiate themselves from those deeply tainted or "lightly stained." Chromosomes, when arrested at mitosis, appear double their size, enabling identification in the slide without magnification. Later the spot would be magnified, revealing the details shown in the drawings: the different bands along the linear structure of each double chromosome. Painter devoted himself to experimental details regarding both slide preparation and the process of assigning identity to the elements that composed a set, such as the one shown in figure $7 . .^{32}$

Impressive as these illustrations may appear today, this image was followed by a "portrait" of a salivary gland chromosome, which appears to be a photomicrograph - taken through the microscope - of the right arm of the third chromosome. This magnified Drosophila chromosome displays impressive precision in the bands and contours. Thus, drawings and portraits presented evidence for Painter's main research question: the extent to which salivary gland chromosomes "corresponded to the element seen in the metaphase plate." 33 To answer this question, he developed research on the chromosome and its genetic meaning with a team

32 Painter, "A new method for the study of chromosome," 179; on Painter's chromosome images and their impact on chromosome mapping, see Raphael Falk, "Applying and extending the notion of genetic linkage: the first fifty years," in Rheinberger and Gaudillière, Classical Genetic Research and its Legacy, 48-70 (London: Routledge, 2004).

33 Theophilus S. Painter, "Salivary chromosomes and the attack on the gene," Journal of Heredity 25, no. 12 (1934): 465-76, on 465. 
of expert assistants, two men and two women: Dr. J. T. Patterson, Mr. Wilson Stone, Miss Bedichek and Miss Suche, referred to as Patterson's technical assistants. ${ }^{34}$ Falk has insightfully reflected on this research. ${ }^{35} \mathrm{My}$ aim here is to include Painter's images, his styles of representing chromosomes and methods for obtaining them, then reconstructing such images out of broken pieces, to show a genealogy of the visual cultures of genetics, based on the production of chromosome images as evidence that guided a way of reasoning about heredity. I suggest the early banding exhibited by Painter and his team of researchers at the University of Texas belongs to this genealogy, as does Lee's drawing for Penrose's introduction to the Denver conference report.

\section{From Plant Chromosomes Onwards}

Botanists were among the earliest researchers to display an expertise in studying and drawing chromosomes of a wide variety of plants, cereals and flowering plants among them. Their illustrations included systematic figures of these chromosomes. In his 1937 handbook on plant cytology, the John Innes Horticultural Institution botanist Cyril D. Darlington, an influential geneticist, exhibits many chromosome images, as did numerous other botanists at John Innes throughout the late 1930s, 1940s and 1950s, to mention only the period covered in this paper..$^{36}$ The style of chromosome drawings, stretched into long, thin shapes, was shared with botanists from other countries, including the Portuguese Narcissus expert, Abílio Fernandes. ${ }^{37}$

In the US, Ann May Lutz stands out in the early history of plant cytogenetics through her detection of polyploidy - when the number of chromosomes more than doubles the basic number - in the evening primrose, Oenothera, in 1907. Her early drawings of the plant's chromosomes participated in the genealogy of shapes assumed by these cellular entities, observed during cell division. ${ }^{38}$ Diagrammatic lines of the phenomena of polyploidy were presented when Albert Blakeslee represented jimson weed in a "somatic diagram." Each chromosome of Datura Stramonium was drawn as a short line, a representation method he

\footnotetext{
${ }^{34}$ Ibid., 468; although signing as a sole author he mentions the names of his collaborators in every paper from at least 1934 .

35 Falk, "Applying and extending."

${ }^{36}$ Cyril Dean Darlington, Recent Advances in Cytology, 2nd ed. (Philadelphia: Blakiston's Son \& Co., Inc., 1937), available at https://archive.org/details/recentadvancesin00darl (accessed May 20, 2020). On Darlington, see Oren Solomon Harman, The Man who Invented the Chromosome. A life of Cyril Darlington (Cambridge, MA: Harvard University Press, 2004).

37 See part of his long list of publications in Abılio Fernandes, "L'evolution chez le genre Narcissus L.," Anales del Instituto Botánico Cabanilles 32, no. 2 (1973): 843-72.

38 On Lutz, see Marsha L. Richmond, "Women in mutation studies: The role of gender in the methods, practices, and results of early twentieth-century genetics," in Campos and von Schwerin, Making Mutations, 11-47.
} 
maintained from the 1920s until the late 1930s (see figure 8), when, experimenting with the effects of colchicine on the same plant, he discovered a trisomy, three instances of a particular chromosome rather than two. ${ }^{39}$ The hallucinogenic jimson weed became an experimental system, the chromosomal diversity of which was schematized in a type of drawing practice that helped to swiftly correlate the size of a plant with chromosome numbers. Short lines as chromosomes were organized to give the impression of a set. The elements were gathered together to represent a match, with the specific distribution of the group including the same geometric contour (Figure 8). Although stylish and comprehensive, the use of these figures did not gain popularity.

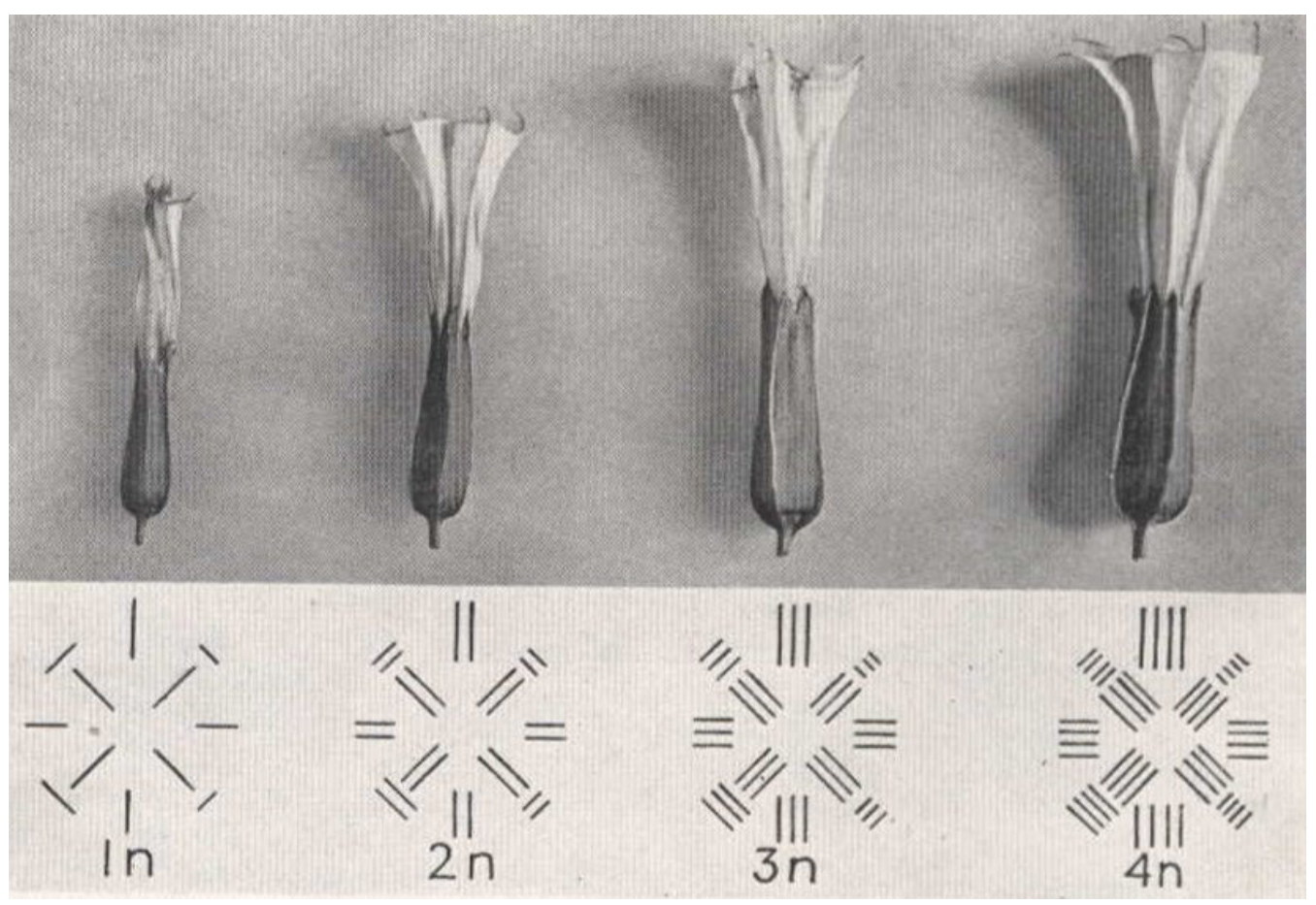

Figure 8 - Series of Datura specimens, the sizes of which correlate with increasing chromosome numbers, from $1 \mathrm{n}$ to successive multiplications. Chromosome diagrams under each specimen show a cytologically "consistent" increase of size, according to Blakeslee and Avery. Albert F. Blakeslee and Amos G. Avery, "Methods of inducing doubling of chromosomes in plants: By treatment with colchicine," Journal of Heredity 28, no. 12 (1937): 393-411, on 408. Reproduced with permission from the American Genetic Association.

The creative type of images a young Charles Ford was drawing by 1936 would not endure either. While collaborating with plant geneticist Reginald Ruggles Gates, at Kings College,

${ }^{39}$ Helen A. Curry, Evolution Made to Order: Plant Breeding and Technological Innovation in TwentiethCentury America (Chicago: University of Chicago Press 2016), chapters 6 and 7; Luis A. Campos, Radium and the Secret of Life (Chicago: University of Chicago Press, 2015), chapter 4. 
London, Ford published a particular drawing of the ring composed of fourteen chromosomes found during Oenothera laevigata cell division (see figure 9). ${ }^{40}$ Evening primroses under the general name Oenothera were collected and studied by Gates, who supervised Ford's PhD. Gates demonstrated the diversity of Oenothera chromosome numbers and named many varieties. ${ }^{41}$
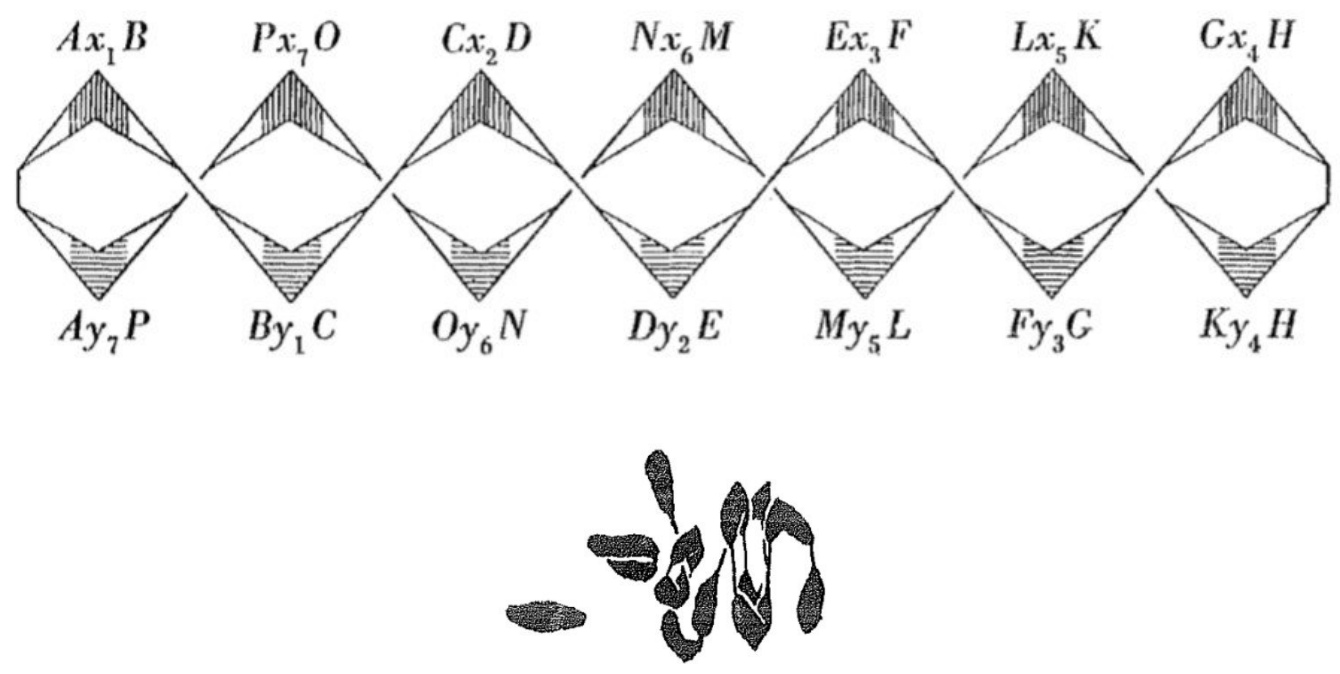

Figure 9 - Above: diagrammatic representation of a ring composed of 14 chromosomes of the evening primrose family, Oenothera. Below: chain of 11 with one chain pair (two chromosomes attached) and one chromosome as seen through the microscope. From Charles E. Ford, "Nondisjunction in Oenothera and the genesis of trisomics," Journal of Genetics 33 (1936): 275-303, on

277, 290 and 284. Reproduced with permission from the Indian Academy of Sciences.

So, throughout the history of cytogenetic practices, chromosomes have been represented in different styles. When the effects of alkaloid colchicine were tested on plants during the $1920 \mathrm{~s}$ and 1930s, Blakeslee himself and many other US botanists observed chromosomes during cell division in the presence of the alkaloid, thus producing artificial polyploidy: that is, inducing the multiplication of chromosomes. ${ }^{42}$ Among the features of colchicine was its capacity to

${ }^{40}$ Charles E. Ford, "Non-disjunction in Oenothera and the genesis of trisomics," Journal of Genetics 33 (1936): 275-303. On Ford and cytogenetics in Britain, see de Chadarevian, "Mice and the reactor"; and Mary F Lyon, "Charles Edmund Ford. 24 October 1912 - 7 January 1999," Biographical Memoirs of Fellows of the Royal Society 47 (2001): 191-201; on Gates, Richmond, "Women in Mutation Studies."

${ }_{41}$ Reginald Ruggles Gates, "VIII-Genetical and taxonomic investigations in the Genus Oenothera," Philosophical Transactions of the Royal Society of London. Series B, Biological Sciences 226, no. 536 (1936): 239-55.

42 On the meaning and practices of polyploidy, see María Jesús Santesmases, "The Biological Landscape of Polyploidy: Chromosomes under Glass in the 1950s," History and Philosophy of the Life Sciences 35, no. 1 (2013): 91-97. On the history of colchicine, see Jordan Goodman, "Plants, Cells and Bodies: The Molecular Biography of Colchicine, 1930-1970s," in Molecularizing Biology and Medicine: New Practices and Alliances, 1920s to 1970s, eds. Soraya de Chadarevian and Harmke Kamminga, 16-41 (London: Taylor \& Francis, 2003). 
arrest, to stop metaphase, so chromosomes could be seen during cell division as clear shapes. ${ }^{43}$ These clear shapes were drawn following the ink drawing style of drosophilists, based on Stevens' mode of drawing, later idealized by the drawings published by the early Drosophila genetics group. Together they produced "the invention of pictorial effects" to represent natural things originating from living beings. ${ }^{44}$ This invention was sustained, used and reproduced, at times with the introduction of small, slight modifications.

By reproducing the practice of making chromosomes - including the preparation of the sample for a slide so chromosomes could be clearly seen - this representation method depicted ink images of chromosomes as enlarged black shapes, with a constriction - the centrosome-dividing each into two arms. Chromosome drawings facilitated their classification, identification and naming based on size and the length of each arm. The image defined the cellular entity, with each chromosome usually surrounded by the full set. Easily described with words for those without in-depth knowledge, the stylized drawing of the chromosome set of each species came to embody the meaning of the term chromosome. The creation of such a visual culture, the consolidation of the meaning of images in biological terms - that is, for an epistemology of biological heredity - involved the circulation of knowledge, of instructions on how to proceed with the samples as laboratory methods. Thus, circulation constructed the growing capacity to reproduce such methods in any laboratory, once instructions were received in an environment where human cytogenetic questions were being posed. ${ }^{45}$

In 1956, when the new number of forty-six human chromosomes was published by Joe Hin Tjio and Albert Levan in the Swedish journal Hereditas, the method for obtaining clear images of chromosomes began to circulate among cytologists and geneticists. ${ }^{46}$ By then, Tjio was spending some part of the year doing research on plant improvement at the Spanish Experimental Station Aula Dei, in Zaragoza, and sometime with Levan at the University of Lund Institute of Genetics. Tjio and Levan presented their images at international congresses, and the small group of researchers working on human chromosomes began to reproduce the recipe included in Tjio and Levan's paper, confirming it by reproducing the method and generating clear images. It involved careful crafts such as preparing a saline solution of very low concentration (hypotonic), the use of colchicine in the culturing media - including the correct culturing concentration, time and temperature - and finally the squashing of the cover glass of

\footnotetext{
${ }^{43}$ On this, see Hsu, Human and Mammalian Cytogenetics.

${ }^{44}$ Ernst H. Gombrich, Art and Illusion: A Study in the Psychology of Pictorial Representation (London: Phaedon,1960); cited by Mauro Turrini, "Continuous Grey Scales Versus Sharp Contrasts: Styles of Representation in Italian Clinical Cytogenetics Laboratories," Human Studies 35, no. 1 (2012): 1-25, on 2.

45 I have developed the concept of circulation in María Jesús Santesmases, The Circulation of Penicillin in Spain: Health, Wealth and Authority (London: Palgrave Macmillan, 2018).

${ }^{46}$ Joe Hin Tjio and Albert Levan, “The chromosome number of man,” Hereditas 42, no. 1-2 (1956): 1-6.
} 
the preparative slide to break the membrane, leaving the chromosomes free and identifiable under the microscope. Skilled cytogeneticists comparable to Levan and Tjio included Charles Ford and John Hamerton in Harwell (UK), Tao-Chiuh Hsu, a US cytogeneticist of Chinese origin, and a handful of others in Europe, Japan and the US. ${ }^{47}$

In their 1956 paper, Tjio and Levan presented visual evidence of the new number of human chromosomes: ink drawings of what were known as "ideograms" of the human chromosomes - extracted from embryonic tissue obtained from an abortion clinic in Lund - were shown on the page following two clear photomicrographs (Figure 10). These images have been published so many times since then that successive editors of the journal Hereditas are accustomed to agreeing to any request.

The images included in Tjio and Levan's paper condensed within themselves an enduring code of chromosome representations in drawings and photomicrographs. Although the attachment of a camera is not as old as the microscope itself, photography had been a renowned practice since William Henry Fox Talbot experimented with images in an attempt "to imprint themselves durably and remain fixed upon the paper." These were Talbott's own words during the 1830s, as he developed a technique that would become what he described as The Pencil of Nature. $^{48}$

Skilled in both photography and slide preparations, Tjio's contribution was not only the preparative slide - a craft shared with other cytogeneticists of the time, including his Swedish mentor, Albert Levan - but the clear photomicrographs. ${ }^{49}$ The method for preparing the slide was explicitly detailed in Tjio and Levan's 1956 paper, but not the process of taking and developing the photographs. This artisan craft involved the camera, lenses, optical levels, developing substances and precise timings, all of which would affect the degree of success: any variances would have been apparent to such a trained cytologist and photographer as Tjio was in $1955 . .^{50}$

\footnotetext{
${ }^{47}$ On Japanese cytogeneticists, see Iida, "Practice and politics." An interesting and complex case is the work of Kodani on human chromosomes in Japan; see Vassiliki Betty Smocovitis, "Genetics Behind Barbed Wire: Masuo Kodani, Émigré Geneticists, and Wartime Genetics Research at Manzanar Relocation Center," Genetics 187, no. 2 (2011):357-66.

${ }^{48}$ William Henry Fox Talbot, The Pencil of Nature (London: Longman, 1844), available at http://www. gutenberg.org/ebooks/33447 (accessed May 20, 2020); Anne Secord, "Talbot's First Lens. Botanical Vision as an Exact Science," in William Henry Fox Talbot: Beyond Photography, eds. Chitra Ramalingam, Mirjam Brusius, and Katrina Dean, 41-66 (New Haven: Yale University Press, 2013).

${ }^{49}$ Soraya de Chadarevian, "Chromosome photography and the human karyotype," Historical Studies in the Natural Sciences 45, no. 1 (2015): 115-46.

${ }^{50}$ Santesmases, "Circulating biomedical images."
} 

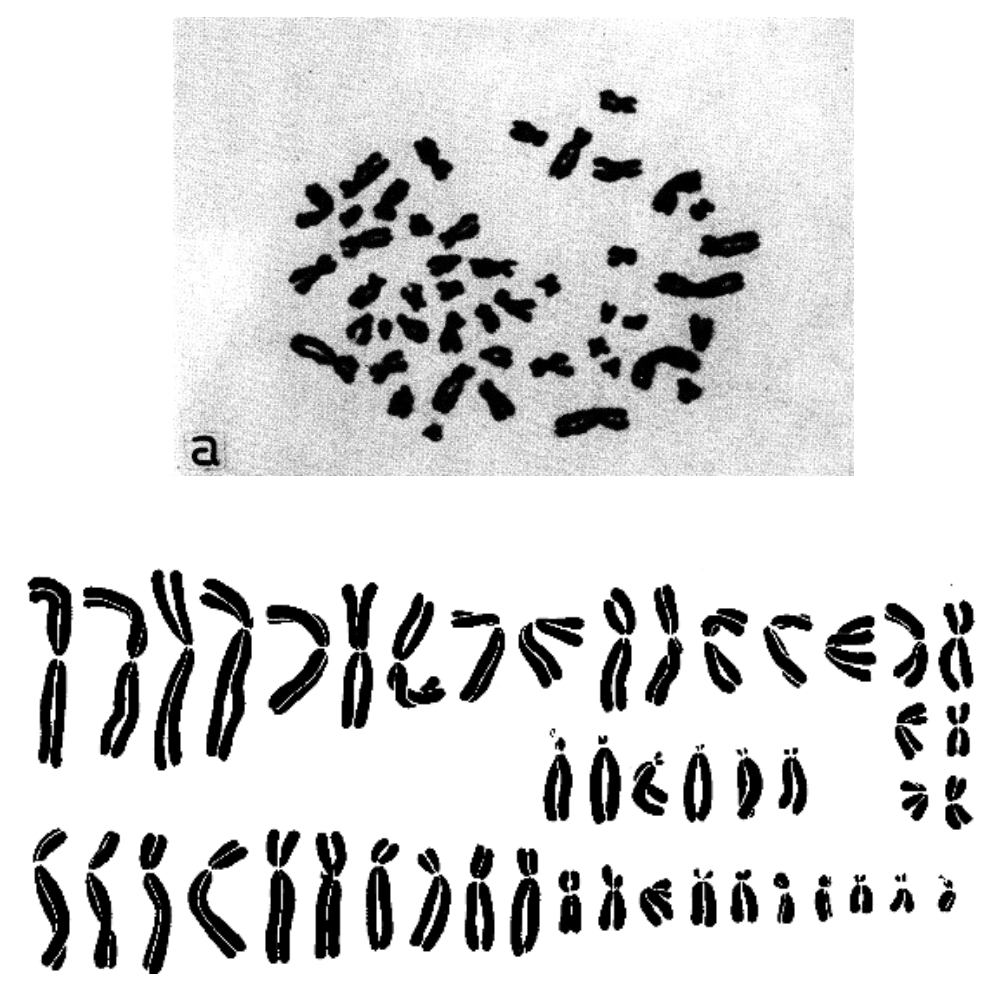

Figure 10 - Images of the new chromosome number of "man" as of 1956. Above, the microphotograph of the 46 human chromosomes reproduced by Joe Hin Tjio; and below the ideogram from Joe Hin Tjio and Albert Levan, "The chromosome number of man," Hereditas 42, no. 1-2 (1956): 1-6. Reproduced with permission from the editor.

The style of the ideogram was also partly new, as here the chromosomes were ordered by size, rather than put together in the position they were observed in the slide magnification, or in a manner inspired by that observation. This practice of ordering had been used by Levan since the late 1930s, when he represented Allium cepa (onion) chromosomes in pairs, "separately drawn"; in 1950, when Tjio and Levan adopted the practice of size ordering for the chromosomes of the wheat and rye hybrid, Triticale (see figure 11); and in his work with the US biomedical researcher and cancer expert Theodor Hauschka, at the Institute for Cancer Research in Philadelphia in the early 1950 s. ${ }^{51}$ It had been Levan's work on cancer chromosomes that had led him to study human chromosomes with Tjio. ${ }^{52}$

\footnotetext{
${ }^{51}$ Albert Levan, “The effect of colchicine on root mitoses in Allium," Hereditas 24, no. 4 (1938): 471-86, on 437; Joe Hin Tjio and Albert Levan, "The uses of oxyquinoline in chromosome analysis," Anales de la Estación Experimental Aula Dei 2 (1950): 21-64; Albert Levan and Theodore S. Hauschka, "Endomitotic reduplication mechanisms in ascites tumors of the mouse," Journal of the National Cancer Institute 14, no. 1 (1953): 1-43.

52 Santesmases, "Human Chromosomes and Cancer."
} 


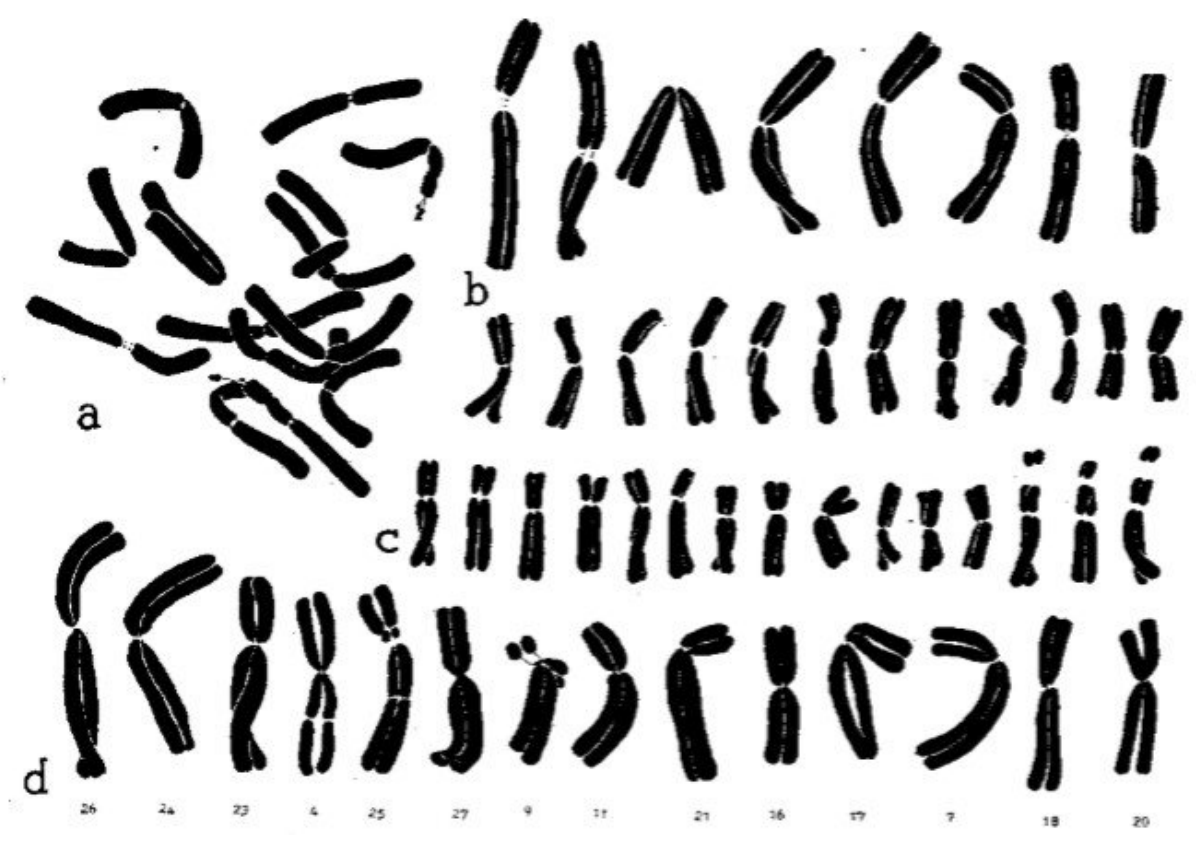

Figure 11 - Chromosomes of "single grain" wheat variety, Triticum monococum (a); of rye, Secale cereale (b); of bread wheat, Triticum vulgare (c); and wheat and rye hybrid Triticale (d), all very likely drawn by Levan. Note not only the similar style of chromosome shaping to that of the 1956 paper on human chromosomes but also the order. Joe Hin Tjio and Albert Levan, "The uses of oxyquinoline in chromosome analysis," Anales de la Estación Experimental Aula Dei 2 (1950): 21-64, on 51.

Reproduced with permission from Estación Experimental Aula Dei.

Creating order out of an image viewed through the microscope was a practice within embryology and natural history. Mr. A. J. Lee followed this in his image for Penrose's introduction to the Denver report. Although the report itself did not include any pictures, a long footnote discusses images: a drawing or photomicrograph of the chromosomes of a single cell was named a karyotype; the diagram - diagrammatic representation - an ideogram. In this framework, Lee's drawing of idealised forms in the Annals of Human Genetics was a diagram and was referred to as such by Penrose in his "Editorial Comment."

In this diagram, chromosomes appear at the moment of mitosis: they have duplicated and are shown in pairs of the commonly-named sister chromosomes, joined at the centromere, a position they take during the metaphase of cell division. In their 1955 book on colchicine, Oliver Eigsti and Pierre Dustin stated that colchicines "acts upon mitosis with great efficiency, high specificity and total selectivity" with the chromosomes "accumulated in pairs." 53 It was the use of colchicine - one of the agents that manufactured clear, precise, contracted

53 Orie Jacob Eigsti and Pierre Dustin, Colchicine: In Agriculture, Medicine, Biology and Chemistry (Ames, Iowa: Iowa State College Press, 1957), 28-29. 
chromosome shapes - which facilitated increased knowledge about cell-division, precisely through experimentation with colchicine mitosis, or c-mitosis. So, every chromosome in Levan's ideograms and those used by Tjio and Levan in 1956 appeared, through the action of colchicine, conjoined in pairs following replication and before division.

Thus, human chromosome ideograms as a schematized representation of the human karyotype were not only a product of the practices of botany, zoology and cytology, but also of colchicine and its promotion of mitosis, of chromosome contraction and drawing skills, a culture of imaging that, as Hsu has argued, was at the origins of human cytogenetic practices. ${ }^{54}$

The influence of the arrangement described as "a diagram of a set of [human] chromosomes drawn from average measurement values" that, following Penrose, I attribute to Mr A. J. Lee from Galton Laboratories at the University College London, is seen in how chromosomes are still represented and visually depicted today. ${ }^{55}$ Not only were ideograms a product of the entire trajectory of chromosome imagery from botany to human cytogenetics, these schematized shapes had their own historical influence on the forms that chromosomes would take from that time forward. This influence exhibits, in essence, a biological ontology - a group of chromosomes - the meaning of which for heredity was embodied in the drawings, photomicrographs and frameworks produced by experts or those who would eventually be regarded as experts. Images explain and describe the process of cell division as chromosomes duplicate and divide.

The impact of this imaging style was swift. In 1958, Tjio was collaborating with Theodore T. Puck at the University of Colorado Medical Center in Denver. In December that year, when Puck was awarded the already prestigious Lasker Award for his work in propagating mammalian cells, he and Tjio published a new ideogram of human chromosomes. In this, following the style of Levan and Tjio's ideogram, they had cut up photomicrographs of a diversity of human chromosome sets, and pasted every chromosome pair - the sister chromosomes linked at the centromere - ordered by size. ${ }^{56}$ This ideogram of photo(micro)graphed chromosomes was indeed based on the previous, drawn one. The order created by the drawing had been preserved in the reconstruction of a photographed set.

The inspiration taken from a drawn ideogram for this composite ideogram of chromosome photographs is revealing, and the results, although originating from a photograph and therefore reliable, look less beautiful, less clear than the drawn ideogram; the magnified images of each chromosome appear with blurred, less precise contours. This cytogenetic epistemological

\footnotetext{
${ }^{54} \mathrm{Hsu}$, Human and Mammalian Cytogenetics.

${ }^{55}$ Hogan, Life Histories of Genetic Disease.

56 See de Chadarevian, "Chromosome Photography"; Joe-Hin Tjio and Theodore T. Puck, "The Somatic Chromosomes of Man," Proceedings of the National Academy of Sciences of the United States of America 44, no. 12 (1958): 1229.
} 
transition from drawing to photograph took place in the era of camera witnessing. ${ }^{57} \mathrm{~A}$ new code was being created, and the representation from a microphotograph was regarded as marvellous, not only by Levan but by many cytogeneticists of the time. While magnification of microphotographed chromosomes created imprecise contours, the superior ontology secured by photography as a witness has usually been taken for granted, despite Svetlana Alpers discussion of the art of describing in Flemish paintings before the advent of photography; her 1983 book has long been an inspiration in the study of visual cultures, not only of the sciences. ${ }^{58}$

A century earlier, Talbot had obtained some of his photographic plates by reproducing drawings, attempting to develop the precision of painting within photography. ${ }^{59}$ Tjio and Puck pioneered the use of photomicrographic ideograms, presenting an alternative to drawing shapes that took full advantage of not only Tjio's skills as a photographer, but of the era of photography, reflecting facts through the chemical reaction of light on a plate: a chemical practice now regarded as more reliable than the drawing hand.

\section{The History of Cytogenetics as One Long Caption: Stabilizations and Renunciations of Chromosome Shapes in the Molecular Era}

Cytogenetics finally became a domain of knowledge, consisting of an ever lengthier caption of successive chromosome images from the early days of cytology until the genome era. ${ }^{60}$ By taking this approach, the history of cytogenetics appears as a long chronological series of drawings, photomicrographs and ideograms, the captions of which provide an historicized text. Magnified photomicrographs replaced skilful drawings at times, particularly from the late 1950 s on, but not forever. Some contributed to stabilizing a type of imaging while others did not; however, all of them informed a visual epistemology of cytogenetics intended to create order out of images while accounting for the biological function of the shapes from which cells divide.

As chromosomes are visible only during cell division, or more precisely during the part of the

\footnotetext{
${ }^{57}$ On Tjio’s photographic abilities, see de Chadarevian, "Chromosome Photography"; on the taking for granted of photographic methods, see Santesmases, "Circulating Biomedical Images."

58 Svetlana Alpers, The Art of Describing: Dutch Art in the Seventeenth Century (Chicago: University of Chicago Press, 1983).

59 Talbot, The Pencil of Nature.

${ }^{60}$ An inspiration for this proposal is the statement on captions not being knowledge in itself, in Geoff Dyer's introduction to John Berger, Understanding a Photograph (London: Penguin, 2013), 4; Spanish version, trans. by Pilar Vázquez, Para entender la fotografía (Barcelona: Gustavo Gili, 2015), 6.
} 
cell cycle when the nucleus divides, since the early days of cytology it has been in the phases of such cell division that chromosomes have been witnessed. Painter and Blakeslee, as well as British botanists such as Darlington, represented replicated chromosomes in pairs, with each chromosome situated beside its sister, or at times as individuals without their partner, already separated. Drosophilist's presented individual sets as well, before replication, as did McClintock. In the 1950s, T. C. Hsu (1952), Makino and Hsu (1954), Levan (1956), and Levan and Hauschka introduced ideograms of X-forms, the two sister chromosomes almost divided but attached through the centromere. ${ }^{61}$ Named colchicine mitosis, this was a space of practices cultivated by Levan since the 1930s onwards. As the name suggests, it was the action of the alkaloid colchicine that arrested cell division at metaphase and kept the identical chromosomes attached. ${ }^{62}$ The clear images of this phenomena have been attributed to Levan, an expert botanist who obtained them in the case of onions (Allium) during the 1930s, before entering human cytogenetics in collaboration with Theodore Hauschka in Philadelphia in the early 1950s. Levan's illustrations, among the first drawings with clear lines, were included in an early review of the features and activity of colchicine by the experts Eigsti and Dustin, and may well have contributed to Stevens expanding the clear chromosome shapes she drew of the genus Diptera, and the renunciation of other kinds of representation, such as the schematized abstractions, both geometric and lineal, by, respectively, Ford, and Blakeslee and Avery. ${ }^{63}$

By the late 1950s, a culture of avoiding chromosome drawings in scientific articles in academic journals had been established, and, lasting to the present day, a popular notion - shared by academic scientists - that photography as a material reality is more reliable than a drawing, despite chemical mediation. A whole reconstruction could be made of an historized visual epistemology shifting from drawings to photo(micro)graphs, even though drawn diagrams still endure in the present genomic era. This, then, was a partial transition: that is, drawings did not disappear altogether as chromosome ideograms are still in use. These characters participated in a culture that stabilized itself in the first representation of human chromosomes: the diagrammatic standard drawn by Mr A. J. Lee and published by Lionel Penrose in 1960.

"A transformation in laboratory practices in the late 1950s made human chromosomes easier to see and assess," states Susan Lindee in her reconstruction of the Denver Conference. Lindee

${ }^{61}$ Tao-Chiuh Hsu, "Mammalian chromosomes in vitro: I. The karyotype of man," Journal of Heredity 43 (1952): 167-72; Sajiro Makino and Tao-Chiuh Hsu, "Mammalian Chromosomes in vitro. V," Cytologia 19 (1954): 23-28; Albert Levan and Theodore S. Hauschka, "Endomitotic reduplication mechanisms in ascites tumors of the mouse," Journal of the National Cancer Institute 14 (1953): 1-43; Albert Levan, "Chromosome studies on some human tumors and tissues of normal origin, grown in vivo and in vitro at the Sloan-Kettering Institute," Cancer 9 (1956): 648-63.

${ }^{62} \mathrm{Hsu}$, Human and Mammalian Cytogenetics; Eigsti and Dustin, Colchicine.

${ }^{63}$ Albert Levan, "Cytological studies in Allium, II Chromosome morphological contributions," Hereditas 16 (1932): 257-94; Eigsti and Dustin, Colchicine: 47-49. 
refers to chromosomes as "historical products," and as she added, "chromosomes as biological and [her emphasis] pictorial objects were negotiated at this meeting." ${ }^{64}$ This essay relies in part on Lindee's sociological perspective, while shifting to visual cultures with Satzinger's approach to Boveri's chromosome images as an inspirational starting point. It aims to present a chronology of images of experiments on various biological material extracted from plants, animals and human beings, the reproduction of which created a visual culture composed of images of different types - diagrams, descriptive drawings, microphotographs - and ways of talking about those images that developed as a grand narrative, a historically long thesis following the similarly long caption composed by the successive captions of each image produced since the early days of cytology, a historized set of "conceptual images," as Martin Rudwick has proposed for geology. ${ }^{65}$

This trajectory of human genetics as a history of images and the skills of drawing, making photo(micro)graphs and diagrams, developed through a reference drawn on the basis of the consensus reached by a small group of early, skilful, human cytogeneticists in Denver in 1960. The creation of standardized chromosome shapes took time, as although imaging produced at successive meetings on the names and shapes of chromosomes illustrates the extent to which the 1960 pattern would eventually become a standard, it was not immediately accepted as such. The image manufactured in 1960 was qualified by Lionel Penrose as a "standard diagram," suggesting there were already aspirations that it would become a pattern, a reference, an image that represented the human chromosome set: that is, the karyotype. The practitioners of human cytogenetics during the 1960s and 1970s do indeed appear to have accepted this image: it was included in subsequent reports of human chromosome meetings. It was in Paris in 1970 when bands were added to these chromosome contours, drawn as the result of experiments with particular colouring and visualizing techniques performed by Lore Zech at the Karolinska Institute in Stockholm during the late 1960s. ${ }^{66}$

The agency of colchicine created a medium of seeing chromosomes during cell division, and its use provided clear images of chromosomes in the preparative slide. These would be drawn using the camera lucida and photo(micro)graphed by attaching a camera to the microscope. In addition to the drawing skills of illustrators, the experimental method was an agent in the strategies of British geneticist Lionel Penrose, and in evidence provided throughout the late 1950 s and the 1960s of increasing cases of disease, disorders and abnormalities correlated with chromosome numbers and shapes.

\footnotetext{
${ }^{64}$ Lindee, Moments of Truth, 91, 94.

${ }^{65}$ Rudwick, "The emergence of a visual language."

${ }^{66}$ Hogan, Life Histories of Genetic Disease; Lindee, Moments of Truth; Santesmases, "Circulating Biomedical images."
} 
This construction of chromosome images as standards and references took place during a transition in the public culture of imaging, during which drawings became somewhat derided as photography secured a superior ontology in its role as witness. This was very much the case within the life sciences, which from the post-World War II era onwards underwent a molecularization: molecular images, however, related to a different historical and conceptual trajectory. ${ }^{67}$ Those scientists who participated in the process of focusing on macromolecules and providing a basis for the epistemology of heredity, relied precisely on such macromolecules and their behaviour during cell division. Meanwhile, the natural sciences were regarded by molecular biologists as old-fashioned, utilizing naturalistic representational styles belonging to the approach of naturalists and specimen collectors. No longer would what was visible to the naked eye and represented with naturalistic and expeditionary codes be regarded as a scientific ontology.

Manufacturing drawings preceded cytogenetics and inspired its development, as shown by the power of images as proof of the basis of biological heredity. What was carried out at the laboratory bench to transform a sample extracted from a human body, whether a living body - a tissue obtained by biopsy or a blood sample - or Tjio and Levan's dead embryo, provided a method for making chromosomes - as it was then phrased - visible, confirming their biological function.

Both the method for obtaining good chromosome images - clear, condensed, and easily identifiable - and the code, the set of signs produced and recognized as chromosomes, were composed through a lengthy pathway of practices by manufacturing imaging styles and patterns. Images and methods were reproduced and made both methods and images reliable.

To reconstruct the meaning of lines and shapes, whether drawn or photographed, they must be placed in the time and geography of the practice that created such lines and shapes. Positionings and idealizations, as well as fully realistic transpositions of the contours and interiors of each chromosome, participated in the emergence of a particular, specific and enduring way of representing the tiny parts of the cell where division begins. Yet the ways of performing the experience of producing visible samples and images representing what the eye had learned to see, created not only the visual culture of contemporary genetics but one of its principal characters: a reference, an image that represents the set of human chromosomes - a diagram of the human karyotype as a standard form to be recognized by those trained and educated in this visual culture.

${ }^{67}$ Soraya de Chadarevian and Harmke Kamminga, eds., Molecularizing Biology and Medicine: New Practices and Alliances, 1920s to 1970s (Oxford-New York: Taylor \& Francis, 2003); Soraya de Chadarevian, Designs for Life: Molecular Biology after World War II (Cambridge, UK: Cambridge University Press, 2002). 


\section{Acknowledgements}

An earlier version of this paper was presented at the workshop Estándares: Perspectivas históricas, epistémicas e institucionales convened by Jesús Vega, Javier Ordónez y Antonio Sánchez at the Universidad Autónoma de Madrid, in June 2018. I would like to thank the organisers and colleagues for the rich subsequent discussion, and the two anonymous referees for their insightful comments and suggestions. I am grateful to Joanna Baines for her skilful copyediting.

\section{Competing interests}

The author has declared that no competing interests exist.

\section{Funding}

Research for this essay was funded by the Spanish Ministry of Economy and Competitiveness (FFI2016-76364). 